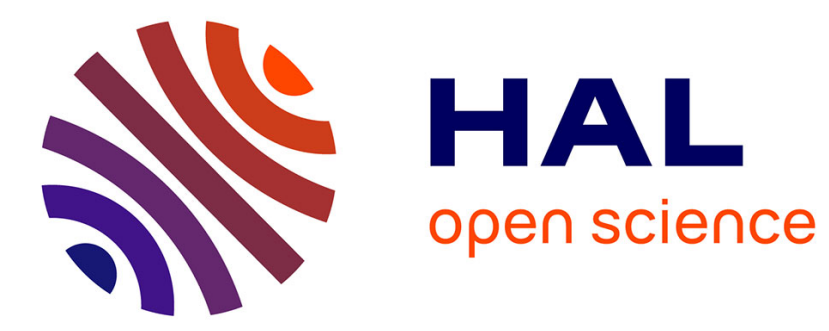

\title{
Discomfort, affects and coping strategies in driving activity \\ Béatrice Cahour
}

\section{To cite this version:}

Béatrice Cahour. Discomfort, affects and coping strategies in driving activity. ECCE 2008 (European

Conference on Cognitive Ergonomics), Sep 2008, Madeira, Spain. pp.45-53. hal-00671729

\section{HAL Id: hal-00671729 \\ https://hal.science/hal-00671729}

Submitted on 18 Feb 2012

HAL is a multi-disciplinary open access archive for the deposit and dissemination of scientific research documents, whether they are published or not. The documents may come from teaching and research institutions in France or abroad, or from public or private research centers.
L'archive ouverte pluridisciplinaire HAL, est destinée au dépôt et à la diffusion de documents scientifiques de niveau recherche, publiés ou non, émanant des établissements d'enseignement et de recherche français ou étrangers, des laboratoires publics ou privés. 


\title{
Discomfort, affects and coping strategies in driving activity
}

\author{
Béatrice Cahour \\ CNRS - LTCI lab. UMR 5141 - Télécom ParisTech \\ 46 rue Barrault, 75013 Paris, Fr. \\ beatrice.cahour@telecom-paristech.fr
}

\begin{abstract}
Psychological comfort/discomfort is a global feeling constructed from the affective states which are lived by the users during the activity. This empirical study is about discomfort and emotions lived during all sorts of driving situations, and it is based on "explicitation interviews" and questionnaires.

The analysis allowed us to specify the categories of uncomfortable situations during driving and their level of discomfort, to develop the underlying cognitive and social sources of discomfort (need of multiple attention; impossible anticipation; loss of control and feeling of un-ability; social image and relation), and to look at how people cope with the disagreeable situations, specifying the different types of coping modes (internal coping, external coping, avoidance).
\end{abstract}

\section{Keywords}

Driving, comfort, discomfort, affects, emotions, coping, subjective experience.

\section{MOTIVATION}

The affective aspects of the activity are now considered as very important to design new assistance systems or new products of all sorts (Norman 2004, Jordan 1998, Nielsen 1993, Helander \& Tham 2003). The willingness to use a tool depends not only on the efficiency and performance that one can achieve by using it, but also on the psychological comfort and discomfort that the users will feel when using it (Cahour \& al 2002). It is then a question of acceptability (Nielsen 1993) and of judgement of the quality of the interaction with this product or system. For instance a driving assistance system may be efficient at a security level but uncomfortable, unpleasant, and the users will then be reluctant to use it. That is why this notion of emotional comfort/discomfort appears very important for evaluation and design. Now that ergonomics is implied in the design of games, cultural devices and communication tools, this importance of the affective aspects of use becomes more obvious since people are seeking emotions and social relations through the use. But still in more classical fields (cars design is one of those) we can see that the emotional comfort/discomfort of the users is a relevant scope of research.

We define the psychological (or emotional) comfort/discomfort as a global feeling which is dynamically constructed through the affective states lived by a user. This user is not only a rational and efficient person but he is also a subject who has a specific sensibility, desires and reluctances. He uses the tools we design for him with his rational way of thinking but also with his sensible way of feeling.

The comfort/discomfort is an affective phenomenon, involving together the body and the mind, but it can have a cognitive or a socio-relational origin, and it is essential to put into light these sources of discomfort in the situated use. We will see how discomfort may be due for instance to an attention load which is too high, to a loss of control, to a difficulty 
to feel present,... but this will be identified via specific emotions and feelings which inform the user that $\mathrm{s} / \mathrm{he}$ is more or less comfortable in this situation of use. These affective states are the cues of comfort and discomfort. Closely related concepts in ergonomics are the notion of well-being (Grosjean \& Ribert 2004) but it is generally used in the context of work situations, and the notions of pleasure (Jordan 1998) and satisfaction (Nielsen 1993) which appears more specific than emotional comfort and discomfort and not explicitly linked to various types of emotional feelings.

Once we have identify a comfort/discomfort, the issue is then to specify what, in the situation of use, is a source of comfort/ discomfort, because that will give us design perspectives. It is not enough to know if globally the users are satisfied by such or such system, the point is to identify more precisely what, when experiencing the use, is a source of disappointment, fear, joy, doubt, surprise, angriness, frustration and so on.

Another important issue is about the effects of these affective states, their impact on the social and cognitive activity. The scientific literature already stresses the impact of emotions on activities, e.g. actions, decision making, creativity, evaluations.

Action tendencies are shaped by some emotions (Oatley \& Johnson-Laird 1987), like going away when frightened, aggressing when annoyed, approaching when seduced. Damasio (1994) has shown how decision making is helped by somatic cues which are linked to an emotional capacity, how people, in their social life, can find various solutions in a rational way but choose between them in an emotional way, a way of recognizing the positive and negative past experiences.

Concerning creativity and problem solving, Isen (1991) demonstrated that people in a positive mood are more creative (in the sense that they produce more associations) and have a different ways of solving problems than people in a negative mood; also they negotiate more easily and are less aggressive in a bargaining situation.
Affective states are finally known to have a congruence effect on recall and on evaluations: when in a positive mood one will recall better positive memories (Bower 1981) and will produce more positive evaluations (about a film, politics or a person to hire, Baron \& Hershey 1988, forgas \& Moylan 1987), and in a negative mood will recall more negative events and will evaluate more negatively. The list of the links between emotional feelings and social and cognitive activities is not exhaustive but still, for all these phenomena, emotions tend to give them a specific orientation or a specific quality.

A last key point for ergonomics is the way people deal with the uncomfortable situation at work or when using technical systems. The management of the emotional situations, called "coping", informs on the personal, social or environmental resources that the subjects can find to cope with the difficulty they encounter. This can inspire also some form of design and give an indication about the urgency to help users, depending on if they can find coping strategies rather easily or if, at the other extreme, they do not find other solution than the avoidance of the threatening situation.

The objectives of the following empirical research were to study the discomfort in driving situations as experienced by the drivers:

- to look at how was the discomfort expressed by the subjects;

- to identify, as largely as possible, the uncomfortable situations encountered while driving;

- to extract the underlying main cognitive and social sources of discomfort ;

- to specify the types of coping strategies of the drivers who try to solve these uncomfortable situations.

The research was financed by the Advanced Technologies Department of Renault (Ergonomic Research Team) and the objective was to find insights for designing new assistance systems, not from the accidental situations, as usually, but from the 
uncomfortable situations, i.e. from the subjective experience of the users of light or intense negative feelings while driving. It then opens the scope from accident-provoking situations to uncomfortable situations, some of which are not turning into an accident but are still a problem for the users and helpful to imagine new technical (or pedagogical) systems.

\section{METHODOLOGICAL APPROACH}

Our methodological approach is based on the subjective experience of the drivers that we document with their subjective reports on situated activities.

We know that emotions can also be apprehended in a more objective way, via the observable behaviour of the subjects, from which some affects can be inferred, for instance from mimics (Ekman \& al 1972), from vocal cues in the verbal discourse (Maffiolo \& Chateau 2003) or from the colour of the face measured on a video recording. But still, these signs of emotions are not sufficient for our ergonomic purpose:

- they are often ambiguous, a mimic can be said as negative but not always differentiate more precisely the emotions.

- affects can be hidden from the social scene, voluntarily or not. A lot of our affective internal movements are not expressed and become invisible for the observer. We can feel them internally but they are not externalized. It may be involuntary or sometimes deliberately chosen, to hide some socially undesirable feelings.

- Also, and that is the biggest problem, these observable behaviours can give some information about the affective state of the user but they do not give the links with the activity; then we can just make hypothesis about what, in the situation, generates such or such affect, but it is often difficult to interpret that instead of the user.
In our study, since we wanted to get a large palette of all types of psychological discomfort in driving situations, we asked the subjects to describe past driving situations where they felt some discomfort, more or less intense, from small trouble to big stress or anxiety, anger, or anything where they felt uncomfortable.

The advantage of the verbalisations of the subjects is that the persons use relatively precise terms to describe their feelings and that they can generally rely them to an element of the situation (ex: "I was afraid of the noise made by my car"). For the observer, there are so many dynamic elements in a driving situation that it is difficult to infer what, in this complex and always evolving situation, is provoking a visible affect of the driver. The source of the fear could have also been a thought of the driver remembering that he had forgotten his keys... and many other possibilities that only the user who is engaged in the situated activity can describe. Also we know that the emotional experience is highly subjective and that it depends on the subject's beliefs, values, history, objectives and concerns (Lazarus 1991). It is consequently difficult for the researcher to infer the emotional dynamic of the subjects. We would then say that the point of view of the users regarding their feelings is the more plausible one since they were the one fully engaged in this situation "with all their subjectivity".

Nevertheless, verbalisations also have their drawbacks. The typical risks when getting verbalisations from subjects describing their activity are the risks of rationalisations and reconstruction. The more we take care of the recall process of the subjects, the more we limit this risk. That is the way we proceeded in a first step, by using a specific interview methodology developed by Vermersch (1994) and called "the explicitation interview". This technique aims at the phenomenological experience of the subject (Depraz, Varela, Vermerch, 2002), and is very cautious on the recall process. One principle is to help the subject to get a vivid memory of the activity by asking questions about the sensorial context. After, we ask questions always linked 
to the situation to avoid generalisations and keep the subject in a position of talk which is focused on what the subject was living (cognitively, perceptively and affectively) during the past experience and not on rational comments and explanations about it (Light 2006).

18 explicitation interviews were gathered with half women and men; 6 subjects of 20-30 years old, 6 subjects of 40-50 years old, and 6 subjects of more than 60 years old.

During these interviews, the 18 subjects described 5 to 12 driving situations that they evaluated as uncomfortable, and we helped them with the explicitation technics. At the end of the interview they were asked to evaluate the intensity of the discomfort of each situation on a 10 points scale.

The transcribed interviews have been analysed with the following grid for each situation described :

- Situation-source of the discomfort ("I was on the highway with friends, at night, we were talking, and suddenly there two highways which joined...")

- affects and sensations ("before I was relax"; "I have been very scared")

- evaluation of the situation ("it was very dangerous")

- perceptions and thoughts ("I was discussing and paying less attention"; "I haven't anticipated the danger")

- actions and coping ("I tried not to panic" "I had looked in the rear-view mirror but vaguely")

- frequency of the situation ("it's very rare")

- other (I don't even know how to analyse precisely what happened")

Then we extracted categories of uncomfortable situations (see below) and built a questionnaire $^{1}$ : for each sub-category, we asked the subjects who had encountered this type of situation to describe it as precisely as they could, and to evaluate the intensity of the discomfort felt during each situation on a 10points scale.

40 questionnaires were filled by drivers of the three classes of age, half men and half women, and analysed with the same grid as the interviews.

\section{FINDINGS}

The analysis of both the interviews and questionnaires gives information about the way people verbalise their affective experiences of driving.

\section{Verbalising affects and discomfort}

First of all we must highlight the fact that drivers talk about their emotional feelings during the driving activity. We gathered many expressions of very diverse emotions, much more than we could imagine by only observing the subjects. Bellow are examples of the diverse ways our subjects talked about their feelings (the higher frequencies are noted, for 12 interviews):

- tension and fear expressed by adjectives, nouns, verbs: e.g. stressed (40), fear (27) anxiety (23), worried (12), afraid, scared, panic, disturbed, or expressions like "in a hurry to go out of this trap".

- anger expressed by adjectives, nouns, verbs or idiomatic expressions: e.g. to get worked up (15), I moan, angry, upset, irritated, annoyed, I fly off the handle.

- other types of affects expressed : e.g. mistrustful, resigned, embarrassed, surprised, frustrated, inhibited, unpleasant, bizarre.

- evaluative verbalisations with an affective aspect and a positive or negative valence : e.g. I don't like...; It's dangerous; it's horrible; it is ridiculous, it's uneasy, it's careless, etc.

- onomatopoeia: they are like an intermediary verbalisation before the words, near the scream, showing that affects are often linked to the body; for instance: 'I felt not 'aaaaah!'

\footnotetext{
${ }^{1}$ The questionnaire construction and analysis was done with S.Khemache, a master student, and J-F.Forzy, researcher in ergonomics from Renault.
} 
but 'oups!" 2 , meaning more or less that it was not an intense fear but a small one.

These various expressions are often associated to modalities of intensity: e.g. very..., a bit...., totally..., not at all..., rather...

During the interviews (which lasted about one hour) the subjects used from 10 to 34 verbal expressions of affective states as above; this indicates that there are some inter-individual differences in the verbalisation of emotions, some subjects describing less emotions than others.

Two factors can explain this difference:

(1) Variations in emotional state when driving: some subjects are generally nervous and worried when driving, some like this activity and some do not, some feel globally secure and some feel globally unsecured, even if the situation is introducing variations in these basic feelings. These are subjects who have a typical profile of driver (calm, unsecured,...). Other subjects cannot be categorised easily, their emotional reactions are more dependant on the situation and on the mood of the day.

(2) Variations in the ability to describe their own feelings: some subjects have more difficulty to share their feelings with the interviewer and to admit when they are not totally controlling the situation. Another point is that some subjects are less reflexively conscious of their feelings than others. These observations make the relation of trust between the interviewer and the interviewee essential. Either the subjects can be preselected (for instance knowing the interviewer), either the interviewer must take time to create a climate of confidence.

\section{Classification of situations of discomfort}

One objective was to specify and categorise as largely as possible the types of elements which generated discomfort during driving activity.

\footnotetext{
2 Translated from french «je ne me suis pas sentie aaaah mais oups!»; the onomatopoeia could be different in english.
}

Below are the various situations of discomfort described. To know which are the most uncomfortable situations judged by the subjects on the 10 points-scales, the results of an Anova test on the 40 questionnaires allowed us to differentiate three different classes of discomfort. We highlight below with a $(\mathrm{q}+)$ the situations of the first class, i.e. the six more uncomfortable ones. Concerning the 18 interviews, the six sub-categories with higher means of discomfort intensity are quoted (i+). The situations noted as more uncomfortable with both techniques, are : to be near a truck, bad weather conditions, and seeing an accident.

\section{- Interactions with other users:}

Intersections; roundabouts; fill into a rapid way (i+); to pass another car (in a small street, at the mountain,...) (i+); to be near a truck $(\mathrm{i}+\mathrm{q}+)$; interactions with careless biker or pedestrian $(\mathrm{q}+)$; driving in crowded big cities (to find the way, to park,...);

\section{- Physical environment:}

Bad weather (skidding) $(\mathrm{i}+\mathrm{q}+)$; visibility problem (especially night) $(\mathrm{q}+)$; unclear road signs;

\section{- Mastery of the driver:}

State/skill of the driver (vigilance, error, attention,...) $(\mathrm{q}+)$; technical mastery of the car (to find the controls, evaluate the width,...); not to find the way and get lost;

\section{- Passengers :}

Disturbing passenger (restless children, judging passenger...) $(\mathrm{i}+)$

- others :

See an accident $(\mathrm{i}+\mathrm{q}+)$.

One interesting result is that we did not find new categories or sub-categories with the questionnaires, but only some new situations of the sub-categories (for instance the alcoholic state for the states/skill of the driver).

Also the means of the six more uncomfortable situations in the questionnaires are from 4,3 to 5,4 , whereas the means of the six more uncomfortable situations in the interviews are 
from 7,1 to 8,1 . One explanation is that the interview helps the subject to recall more vividly the situations of driving and the emotions associated, whereas, when they fill by themselves the questionnaires, they do not reach such a vivid recall and they sub-evaluate the feelings they had at this moment because they are more distanced from the situation they lived.

\section{Underlying cognitive and social sources of discomfort}

From these different situations of discomfort described by the subjects, were extracted more general underlying cognitive or social sources of discomfort.

\section{- Need of multiple attention}

Previous studies have shown that there is a focused attention on a source of worry (Boadbent \& Broadbent 1988). In our study, several subjects said that being obliged to have a sustained attention on an event which disrupts the attention allocated on the road (like restless children, an impatient driver behind, or discussing with a passenger) is a source of stress and worry because they add supplementary activities (monitoring the risk generated) and distracts from the road events; they must consequently have multiple attention and it is costly and tiring. For instance D. described: "Once when I was driving the children to a football match, there was a boy with us, troublemaker, disruptive. He opened the windows, played up, looked behind, made a face when we stopped; it was stressful; because I was forgetting a bit the road, I could not concentrate, it was a highway then a moment of inattention and that's the way one has an accident; I slowed down and said "that's enough, calm down! I's dangerous, I need calm", but he did not understand..."

Same type of phenomenon in the places where people come from various directions, like big cities, ring roads, roundabouts: the potential dangers are numerous and a sustained multifocal (and uncomfortable) attention must handle the potentially dangerous events among these multiple movements. The focus of attention must then be distributed on several objects in different places.

\section{- Impossibility of anticipating}

When acting, a subject is always in a system of wait relatively to the effect of her action, to the behaviour of others, and more generally to the evolution of her immediate environment (Berthoz 1997). Rimé (2005) stresses that the most distinctive source of emotions is the breakdown in the flow of continuity of the link between the individual and his environment. The subjective anticipations are sometimes deceived, mistaken, and what happens may be surprising and generate an uncomfortable feeling, often associated with fear and surprise (linked to the loss of control of the situation, our following point). It is the case of a subject who was waiting at a stop at night and waiting for the two lights of a potentially dangerous car coming, but then it is a motorcycle which arrived and that she did not see; "I was really waiting to see two lights each time; I've been really frightened; happily the motorcycle could go on the second line". Same frightening feeling when a subject drives on a highway which joins suddenly another highway, much more crowded, and she must feel into very quickly, with a feeling of terror ("I've been really very scared"). This need of anticipation varies according to the subjects: some woman even says that she is afraid when she has to take a route that she does not know yet, because she does not know in advance where there will be lights, crossroads, etc. Also this need of anticipation may vary with the age, and a feeling of mistrust of the other drivers' behaviour seems to grow with time and to lead to more anticipation (this observation cannot be generalized yet). Some woman of 45 years old, describing her accident at a crossroad with a man at a stop who had not seen her coming on the left side, says: "he was discussing with someone, the head turned the other way, very busy, I should have been careful... today automatically I would have not trust him". 


\section{- Loss of control and feeling of un-ability}

There is a loss of control when the subject looses the mastery that he usually has on his own action or on an environmental element, when an action is detained or impossible. The power that he generally has on the environment is not efficient anymore, he would like to do something but he is not able to. That is the case of one subject who slips on a patch of ice and the driving procedures he generally uses are not efficient; he then feels "irritated", "frustrated", "angry". Was also described the case of some driving assistance systems to which the driver must delegate one part of his power of action (the speed control); when the anticipation of an effect of an action on the system is wrong, and there is an incoherence between the waited effect and the observed one, one subject says it was "very unpleasant", "very embarrassing". There is a breakdown between the usual mastery and control, and the sudden un-ability to act efficiently. A last example is the fear of the pedestrian suddenly crossing the road and it is too late to stop; for a subject, only the idea of this situation of dramatic helplessness is "hell", "the complete horror", and only the idea of this situation when he drives in town may be frightening.

\section{- Social image and social relations}

The previous discomforts described were based on cognitive processes, but the social image of oneself and the relationships with other drivers and passengers can also be a very important source of discomfort during the activity. A subject talks about the discomfort of driving with a passenger who judges her driving actions in a critical way; she then feels like an incompetent driver and feels "stressed", "nervy". Also when using a cruise control system making the speed constant, a driver describes that sometimes in a descent he is overtaken by a car; when the road goes up again, the other car slows down but his own car continues with the same speed, and overtakes the other driver; he then feels " $a$ bit embarrassed... there is this uneasy feeling of looking like some unpleasant driver, having this image of someone who behaves badly, it's not terrific... when I overtook him I thought "oh la la! he will be angry, so I avoided looking at him because I thought his gaze will kill me". It is also the social relation which is at stake when a subject tells us how he got out of his nerves because of a driver in a hurry who wanted to pass him on a highway; "I did'nt want to move(...) lights signal, horn... it was a rather stressful situation, after I was also a bit angry, I don't like to let the others bother me"; it is a relation of power here which is the origin of a stress and fear. These cases indicate the affective discomfort lived by the subjects when it is not possible to preserve their face, i.e. their social image, or the face of the others, as Goffman's concept of face work (1959) explains it (Cahour 2008). There is also a need to be recognised and not to be aggressed.

\section{Ways of coping with the uncomfortable situations}

The notion of coping corresponds to the ways of managing an emotional situation; it has been defined by Folkman \& Lararus (1984) as the cognitive and behavioural efforts of an individual to manage internal and external demands that he/she evaluates as overcoming his/her present resources. Problem-focused coping are efforts to do something active to alleviate stressful circumstances, whereas emotion-focused coping involve efforts to regulate the emotional consequences of stressful events. From our data, we preferred to distinguish the three following types of coping: self-centred where the subjects try to actively adapt their feelings and actions to the situation; environment-centred where the subjects want to adjust the environment to manage the emotional situation; avoidance, which, in the literature, is often integrated in other categories.

\section{- The internal coping, self-centred}

There is internal coping when the subject is active towards himself or towards the world around; he seeks how to adapt to the situation by creating different actions, concrete or mental, and to adjust directly, by himself, to the uncomfortable situation. It may be (1) by 
modification of his/her internal state (emotionfocused coping): "I ask myself to stay calm", "I try not to think about that", "I stay firm when someone is pushing behind", before a long trip "I wrote the route, I slept well, I left one day before to drive during the week... I had all a protocol around to be reassured"; (2) by procedures, actions or perceptive orientations: slowing down, being attentive or concentrated, developing driving strategies like imposing oneself in a roundabout ("when I am at the point to go into the roundabout, I must be very careful to be able to start very fast, to move off as in the starting-blocks, otherwise I can easily have an accident") when afraid of slipping ("when there is black ice, I start more than one hour before and I try to take more used ways").

\section{- The external coping, environment- centred}

There is external coping when the subject tries to transform the environment, human or material, to adjust this environment to his own needs during the uncomfortable situation. It may be performed by (1) requiring human help, like passengers helping for the orientation, for the perception of the environment ("when I arrive at the ring road, I'm very concentrated and I ask the passengers to look with me"), or for staying awake ("when I was getting asleep this night, I asked the kids to talk to me, it helped"); (2) using an assistance system or other artefacts, like an ABS to avoid slipping, guidance system not to get lost ("since I have bought a TomTom, I feel a bit better in big cities"), rearview mirror getting dark and curtains to avoid the sun in the eyes; (3) Transforming the infrastructure or the rules, like lowering the speed limit ("especially for the vans, too dangerous" said one subject), building roundabouts or putting stops at the risky crossroads ("here they've installed a roundabout, we cannot stop, we can only slow down and we must fit into the traffic...they should put a stop! They should put something there!").

\section{- The avoidance of the uncomfortable situation}

The avoidance mode of coping is the active choice of the subjects to avoid a certain type of environment that they find too uncomfortable, because risky or stressful for instance. He then chooses not to drive in this environment. Avoidance is a mix of self and environment centred coping. For example, people avoid big cities, some difficult roundabouts, driving at night, driving in bad weather conditions, driving alone for a long trip, roads where there are limit controls, driving in the mountain... It seems that older people are more often avoiding uncomfortable situations of driving, but it is not yet clear if it is because the same situations are more uncomfortable for them, or if their critical threshold of comfort is lower than younger people.

\section{DISCUSSION}

This empirical study about discomfort and emotions lived during driving situations allowed us to specify the categories of uncomfortable situations, to develop the underlying cognitive and social sources of discomfort and to look at how people cope with the disagreeable situations, specifying the different types of coping modes.

One point which appears important and original, and which can be generalised to other dynamic situations of human activity are the underlying cognitive and social sources of discomfort. It is important to identify what, in the use of different tools, are the main axes of negative experiences. Of course, to know about the positive experience is important too, but in risky activities, it is crucial to know when people do not feel at ease when acting, and to reduce discomfort is the first way to reach psychological comfort, and to design innovative assistance systems.

Considering design, the study of comfortable and uncomfortable situations allows us to open the scope from breakdowns and accidental situations to more situations which can have a repugnant effect (the extreme leading to avoidance). Her we have now a global image 
of these driving situations and we can chose to focus on one of these situations for designing help systems. For instance now we will focus on highway insertions and other situations of risky interactions between drivers, comparing young drivers and seniors, through fine-grain analysis of the activity, to suggest design tools.

The experience of the users, from their own point of view, is an indispensable step to study emotional comfort (even if we can complement them with observable data). The on-depth interviews and opened questionnaires that we used for having the subjects describe their lived experiences are complementary techniques: the "explicitation interview" helps better the subject to be more in contact with a vivid memory of the situation; we then think that these interviews are richer and more reliable than the questionnaires, but they are time-consuming and the questionnaires may be a complementary solution to this limit. Still an interview cannot be improvised, it is a complex savoir-faire, and the interview techniques and relation of trust are key points for their reliability.

\section{ACKNOWLEDGMENTS}

We thank the Ergonomic Research Team of Renault (DTA, Guyancourt) which has financed this study, and especially JeanFrançois Forzy for his fruitful comments and exchanges. We also thank Sandra Khemache for her work on the questionnaires.

\section{REFERENCES}

Baron, J., \& Hershey, J. C. (1988). Outcome bias in decision evaluation. Journal of Personality and Social Psychology, 54, 569-579.

Berthoz A. (1997). Le sens du mouvement, Paris : Odile Jacob.

Bower G.H. Mood and memory. American psychologist, 36, 129-148 (1981).

Broadbent D.E., Broadbent M. Anxiety and attentional biases: state and trait, cognition and emotion, 2, 165-183 (1988).

Cahour, B., Lorant, F., \& Sanchiz, F. (2002). Use of teleconferencing : perturbing cognitive and social comfort? Proceedings of ECCE'02, 7-10 septembre 02, Catania, Italy.

Cahour B. (2008). Affects management and protection of the relation in cooperative interactions, COOP Conference (Design of Cooperative Systems), Workshop proceedings "Affective aspects of cooperative interactions", Carry-le-Rouet, may $20^{\text {th }}$.

Clore, G. L., \& Gasper, K. (2000). Feeling is believing: Some affective influences on belief. In N. Frijda, T. Manstead, \& S. Bem (Eds.), Emotions and Beliefs: How Feelings Influence Thoughts (pp. 10 - 44). New York: Cambridge University Press.

Damasio A.R. (1995). L'erreur de Descartes; la raison des émotions, Paris : Odile Jacob (V.O : 1994).

Depraz, N., Varela, F., \& Vermersch, P. (2002). On becoming aware. Amsterdam : Benjamins.

Ekman, P., Friesen W.V., \& Ellsworth, P. (1972). Emotion in the human face. New York: Pergamon.

Folkman S., Lazarus R. (1984). Stress, appraisal and coping, New-York: Springer.

Forgas JP. and S. Moylan S. (1987). After the movies: the effects of transient mood states on social judgments. Personality and Social Psychology Bulletin, 13, 1987.

Goffman, E. (1959). The Presentation of Self in Everyday Life. New York: Doubleday.

Grosjean V. \& Ribert Van de Weerdt C. (2004). Emotions at the workplace; from cognitive ergonomics to well-being ergonomics, in Reed D.J., Baxter G., Blythe M. (Eds.) Living and working with technology, ECCE 12, 12-15 sept. 2004, York (UK), p.121-126.

Helander M.G. \& Tham M.P. (2003). Hedonomics : affective human factors 
design, Ergonomics, vol.46, $\mathrm{n}^{\circ} 13 / 14$, 1269-1272.

Isen, A.M. (1993). Positive Affect and Decision Making, in: Lewis, M., Haviland, J.M. (Eds.), Handbook of Emotions, Guilford, New York, pp. 261-277.

Jordan P.W. (1998). Human factors for pleasure in product use, Applied ergonomics, 29, 1, 25-33.

Lazarus, R.S. (1991). Emotion and adaptation.

New York: Oxford University Press.

Light A. (2006). Adding method to meaning; a technique for exploring people's experience with technology, Behaviour and Information Technology, vol 25, $\mathrm{n}^{\circ} 2$, 175-187.
Maffiolo V. \& Chateau N. (2003). The emotional quality of speech in voice services, Ergonomics, Vol 46, n ${ }^{\circ} 3-14$, 1375-1385.

Nielsen J. (1993). Usability engineering, Academic Press, Boston.

Norman D. A. (2004). Emotional design, New-York: Basic Books.

Oatley K. \& Johnson-Laird P.N. (1987). Towards a cognitive theory of emotions, in L.L.Martin \& A. Tesser (Eds), Goals and affect, Hillsdale, NJ, Erlbaum.

Rimé B. (2005). Le partage social des émotions, Paris : PUF.

Vermersch P. (1994). L'entretien d'explicitation, Paris : ESF. 